\title{
PSA Level Less than Thirty
}

National Cancer Institute

\section{Source}

National Cancer Institute. PSA Level Less than Thirty. NCI Thesaurus. Code C142128.

A blood concentration of prostate specific antigen less than $30 \mathrm{ng} / \mathrm{mL}$. 